\title{
Metastatic squamous cell carcinoma of the skin with clinical response to lapatinib
}

\author{
John D. Strickley ${ }^{1}$, Aaron C. Spalding ${ }^{2}$, M. Tye Haeberle ${ }^{3}$, Timothy Brown ${ }^{3}$, Don A. Stevens ${ }^{2}$ and Jae Jung ${ }^{2,3^{*}}$
}

\begin{abstract}
Background: Lapatinib is a tyrosine kinase inhibitor that blocks the HER2 receptor and is typically used in the setting of metastatic breast cancer. Both ERBB2 (HER2) and ERBB3 (HER3) belong to the same family of receptor tyrosine kinases. Dimerization of these receptors leads to activation of cell proliferation and survival pathways, granting oncogenic potential to dysregulated ERBB/HER receptors. Next generation sequencing (NGS) of tumors has ushered in a new era of personalized oncology therapy and has the ability to detect mutations in ERBB receptors.

Case presentation: We present a patient with metastatic cutaneous squamous cell carcinoma who failed surgery, radiation, and anti-PD1 therapy, but showed clinical response to a drug targeting an ERBB3 mutation identified with NGS. Following initiation of the drug lapatinib, this patient exhibited dramatic tumor regression in the skin, soft tissue, bone and nerves.

Conclusions: Cutaneous squamous cell carcinoma is the 2 nd most common skin cancer in humans and future investigation of ERBB2 targeted therapies may provide an effective treatment strategy for patients with mutations in the ERBB2/3 pathway.
\end{abstract}

Keywords: Metastatic cutaneous squamous cell carcinoma, Lapatinib, ERBB3, Next generation sequencing

\section{Background}

Lapatinib is a tyrosine kinase inhibitor used in the setting of ERBB2/HER2 positive metastatic breast cancer [1]. ERBB3 (aka HER3) resides within the same family of receptor tyrosine kinases. In the skin, this family of receptors play a major role in the regulation of keratinocyte proliferation and differentiation, thus have significant oncogenic potential [2]. Here we describe a case of cutaneous metastatic squamous cell carcinoma with an ERBB3 mutation that showed significant improvement in response to lapatinib.

\section{Case presentation}

A man in his 80 s presented with 2 years of recurrent cutaneous squamous cell carcinoma of the left temple (Fig. 1) with zygomatic bone metastasis. He also had significant unilateral hearing loss secondary to perineural involvement. The 2 years of therapy preceding evaluation

\footnotetext{
*Correspondence: jae.jung@nortonhealthcare.org

2 Norton Cancer Institute, 315 E. Broadway, Louisville, KY 40202, USA

Full list of author information is available at the end of the article
}

in our oncodermatology clinic is described below. In addition to Mohs micrographic surgery, the patient had also received two rounds of adjuvant radiotherapy. In the first round of radiotherapy, the patient received a total dose of 5000 cGy in 25 fractions delivered with 3D conformation irradiation to the tumor bed and facial nodal basins. Eight months later, a bony metastasis of the mandible led to another 5000 cGy dose, which was delivered in 25 fractions using intensity-modulated irradiation tracking along the $\mathrm{V} 2$ branch of the trigeminal nerve to the ipsilateral skull base and encompassing the cavernous sinus. Yet another bony metastasis was discovered 5 months later, at which time he consented to 5 cycles of off-label, palliative, compassionate-use nivolumab monotherapy. However, following 2 months of nivolumab treatment, repeat MRI showed continued tumor progression. At this time he presented to our clinic complaining of a 3 week history of a rapidly enlarging painful nodule over his left zygoma. Tumor genomic analysis of the nodule using next-generation sequencing (FoundationOne ${ }^{\circledR}$, Cambridge, MA) revealed a somatic missense (R135C) mutation in the ERBB3/HER3 gene, as well as multiple 


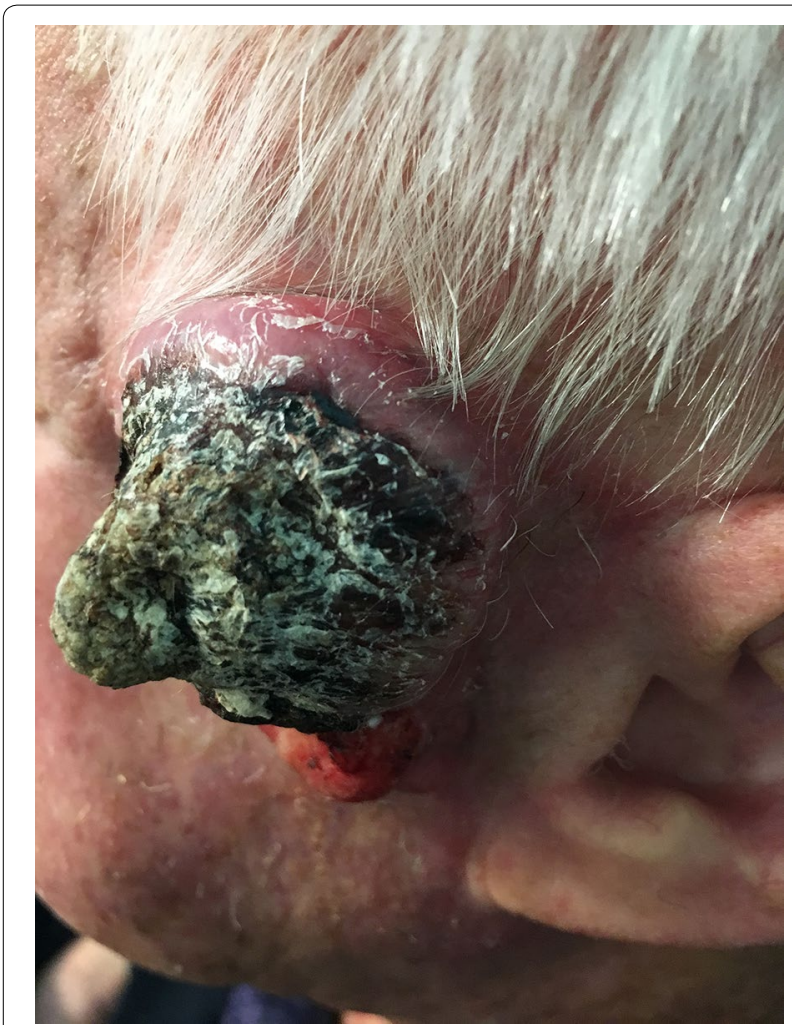

Fig. 1 Clinical appearance of the recurrent squamous cell carcinoma of the left temple with zygomatic bone metastasis
Table 1 List of mutations identified in next-generation sequencing with potential treatments, adapted from the patient's FoundationOne ${ }^{\circledR}$ report

\begin{tabular}{|c|c|c|}
\hline Mutation & Description & Potential treatments ${ }^{a}$ \\
\hline ERBB3 & $\mathrm{R} 135 \mathrm{C}$ & $\begin{array}{l}\text { Lapatinib, trastuzumab, afatinib, } \\
\text { pertuzumab, ado-trastu- } \\
\text { zumab emtansine }\end{array}$ \\
\hline NF2 & Q400 & $\begin{array}{l}\text { Everolimus, temsirolimus, FAK } \\
\text { inhibitors, lapatinib, trametinib }\end{array}$ \\
\hline CDKN2A & $\begin{array}{l}\text { P16INK4a D84Y and } \\
\text { p14ARF 98L }\end{array}$ & $\begin{array}{l}\text { Abemaciclib, ribociclib, palbo- } \\
\text { ciclib }\end{array}$ \\
\hline CARD11 & $\mathrm{R} 888 \mathrm{C}$ & NF-kB inhibitors \\
\hline FAT1 & C $3738 \mathrm{fs}^{*} 12$ & \\
\hline LRP1B & G4199E & \\
\hline RUNX1T1 & R394W & \\
\hline TERT promoter & $-139 \_-138$ CC $>$ TT & \\
\hline TP53 & $\mathrm{R} 196 *, \mathrm{R} 282 \mathrm{~W}$ & $\begin{array}{l}\text { AZD1775, APR-246, SGT-53, } \\
\text { CHK1 inhibitor with irinotecan, } \\
\text { kevetrin }\end{array}$ \\
\hline
\end{tabular}

In the FAT1 and TP53 mutations, the "**" denotes a mutation in a stop codon. In the FAT1 mutation, " $\mathrm{fs}$ " denotes a frameshift mutation. In the TERT promoter mutation, "-" denotes the affected nucleotide, "_" denotes the range of affected residues, and " $>$ " denotes a substitution mutation

a Not all listed treatments are FDA-approved and some are drawn from data found in preclinical and/or early clinical studies

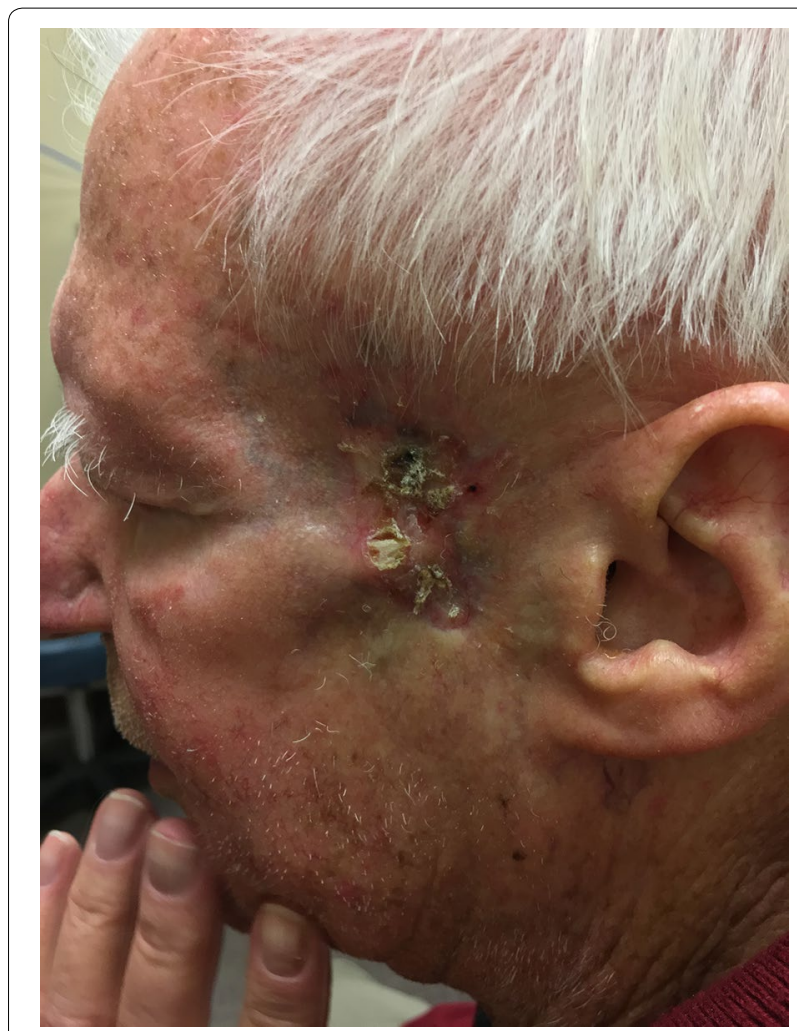

Fig. 2 Clinical appearance of the tumor following surgical debulking and 6 months of lapatinib and nivolumab therapy

other mutations (Table 1) and a high tumor mutation burden (75 mutations per megabase).

In an effort to target the ERBB3/HER3 mutation, therapy with $1,250 \mathrm{mg}$ of lapatinib daily in combination with $240 \mathrm{mg}$ nivolumab every 2 weeks was initiated. Additional tumor debulking in conjunction with cryotherapy to the base of the lesion was performed by our Mohs surgeon. Significant improvement in the clinical size of the lesion was noted after 2 months of lapatinib therapy. After 6 months, there was continued clinical improvement (Fig. 2) and MRI showed significant regression of muscle, nerve, and bone involvement (Fig. 3). The patient experienced a significant decrease in narcotic pain medication dependence and improvement in hearing of the ipsilateral ear. Other than fatigue, he experienced no side effects from this therapy.

\section{Discussion}

This patient's squamous cell carcinoma possessed a mutation in the ERBB3 (aka HER3) gene which encodes a receptor belonging to the human epidermal growth factor receptor (HER) family. Dysregulation of the HER family of receptors is most commonly implicated in breast cancer. Although studies of cancer involving the skin are 

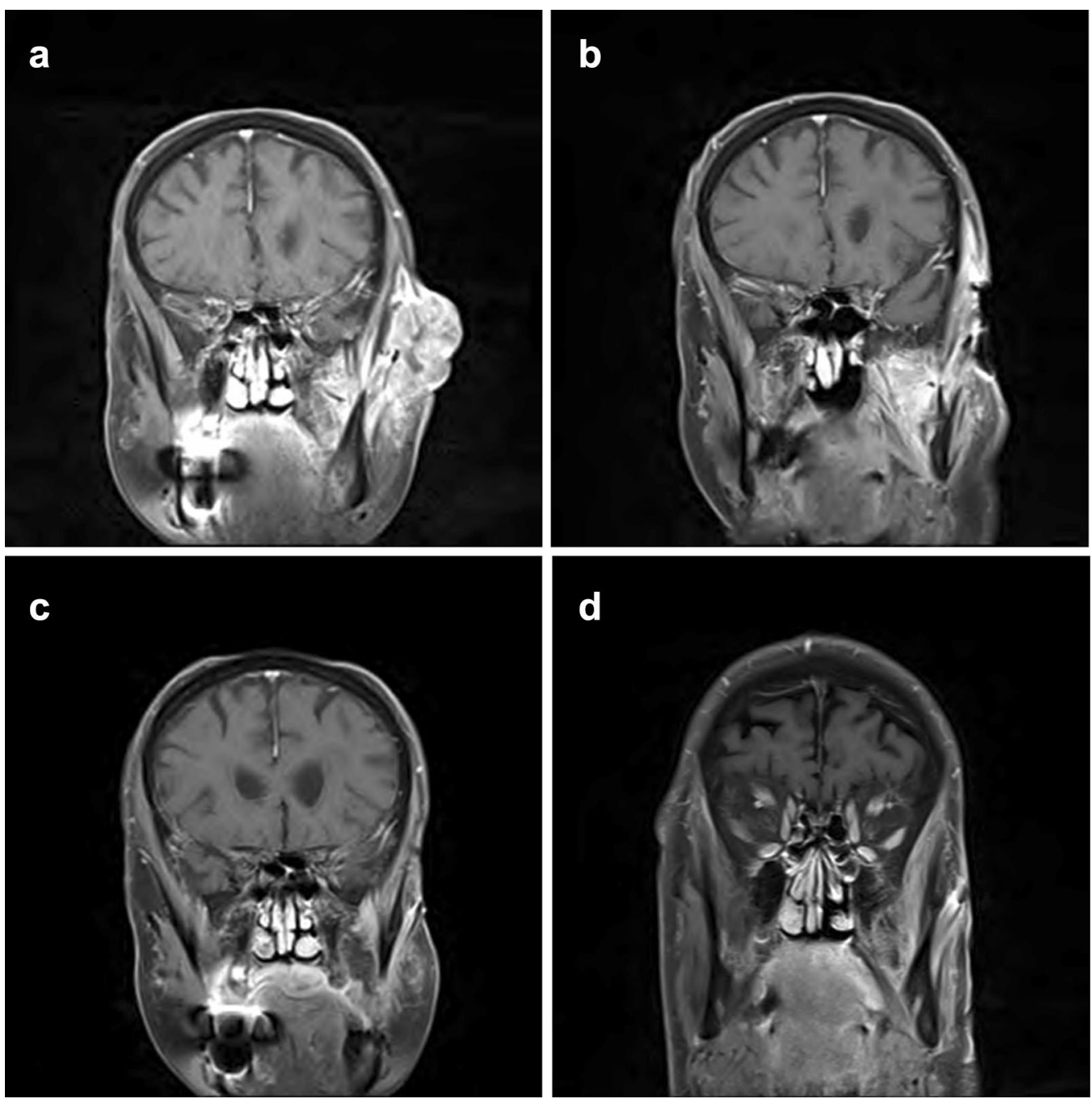

Fig. 3 a-d Coronal T1+ Gadolinium MRI demonstrating $3.2 \times 3.8 \times 4.8 \mathrm{~cm}$ heterogeneous mass and progressive direct bone invasion extending to the junction of the left temporal bone and zygomatic arch. There is involvement of the deep left parotid gland at the level of the facial nerve with evidence of perineural extension along the $\mathrm{V} 3$ nerve to the foramen ovale. Figure $1 \mathrm{~b}$ through $1 \mathrm{~d}$ demonstrate dramatic improvement in the patient's tumor burden

limited, overexpression of ERBB3 has been demonstrated in squamous cell carcinoma, basal cell carcinoma, and melanoma [2,3]. One preclinical study has shown that deletion of the ERBB3 gene provided significant skin cancer protection in mice, suggesting an important role for ERBB3 in skin carcinogenesis [2].

Signal transduction of HER receptors requires dimerization with another receptor within the family. ERBB3 has little ability to transduce signal via homodimerization, thus it relies on pairing with others, most notably ERBB2 (aka HER2). This combination of receptors has been found to be coexpressed more frequently in nonmelanoma skin cancers when compared to normal skin [3]. The ERBB2 and ERBB3 heterodimer appears to be the most oncogenic dimeric combination [4]. The strength in this pairing lies in ERBB2's potent stimulation of the mitogen-activated protein kinase (MAPK/ERK) pathway, and ERBB3's stimulation of the phosphatidylinositol 3-kinase (PI3K) to AKT cell-survival pathway [5]. These findings suggest that this oncogenic heterodimer may be involved the carcinogenesis of skin cancers and could be a target of therapy.

Lapatinib is a dual tyrosine kinase inhibitor of ERBB1 (aka EGFR) and ERBB2 which is FDA-approved for the treatment of ERBB2 positive metastatic breast cancer. In vitro, this drug was shown to be more efficacious than other drugs (e.g. trastuzumab) when a given to cancer cells with ERBB3-activating somatic mutations, similar 
to the mutation described in this patient [6]. Our patient was given lapatinib which led to marked clinical improvement, exhibited by a significant decrease in tumor size, pain, and the return of his hearing.

Although the exact mechanism of this patient's clinical response is unknown, we postulate that synergistic tumor destruction mechanisms enhanced the immune activation of anti-PD1. As in melanoma, it is likely that tumor recognition and destruction are dependent on the development and recognition of neo-antigens. Not all mechanisms that increase tumor destruction generate viable tumor antigens, for example, in a mouse model, cryotherapy with liquid nitrogen generated nearly 3 times as many tumor specific T cells as radiofrequency ablation $[7,8]$. In our patient, we suspect that adjunctive measures, including tumor debulking surgery and liquid nitrogen cryotherapy, also contributed to his remarkable clinical response. Of note, it was difficult to identify a surgeon willing to perform debulking surgery for this patient even though debulking procedures are well known to provide palliation and augment systemic therapy in other tumor types [9].

Cutaneous SCC is the second most common malignancy and although surgery may be curative in local disease, effective therapy for metastatic disease remains elusive. The metastatic rate for primary tumors on sunexposed skin is $5.2 \%$ and overall metastatic rate is $11 \%$. Overall 5 -year survival rate is $26.8 \%$ from all cutaneous sites [10]. Future study of HER2 targeted therapies may provide an effective treatment strategy for cutaneous squamous cell carcinoma patients with mutations in the HER2/3 pathway, including those with advanced disease.

\section{Abbreviations}

NGS: next generation sequencing; HER: human epidermal growth factor receptor; MAPK/ERK: mitogen-activated protein kinase; PI3K: phosphatidylinositol 3-kinase; EGFR: epidermal growth factor receptor.

\section{Authors' contributions}

JDS drafted and edited the manuscript. ACS provided radiologic images and figure legends. MTH revised the manuscript and contributed expertise in dermatologic oncology and dermatopathology. TB was involved in the patient's care and helped revise the manuscript. DAS was involved in the patient's care and helped revise the manuscript. JJ was involved in the patient's care and provided guidance for the manuscript. All authors read and approved the final manuscript.

\section{Author details}

1 University of Louisville School of Medicine, 323 E Chestnut St, Louisville, KY 40202, USA. ${ }^{2}$ Norton Cancer Institute, 315 E. Broadway, Louisville, KY 40202, USA. ${ }^{3}$ Division of Dermatology, University of Louisville School of Medicine, 3810 Springhurst Blvd, Ste. 200, Louisville, KY 40241, USA.

\section{Availability of data and materials}

The datasets used and/or analysed during the current study are available from the corresponding author on reasonable request.

\section{Consent for publication}

The patient has consented to have the medical information and photographs included in this manuscript to be published in a medical journal.

Ethics approval and consent to participate

Not applicable.

Funding

The content of this manuscript was not funded.

\section{Publisher's Note}

Springer Nature remains neutral with regard to jurisdictional claims in published maps and institutional affiliations.

Received: 25 May 2018 Accepted: 14 August 2018

Published online: 28 August 2018

\section{References}

1. Wu Y, Amonkar MM, Sherrill BH, O'Shaughnessy J, Ellis C, Baselga J, Blackwell $\mathrm{KL}$, Burstein HJ. Impact of lapatinib plus trastuzumab versus singleagent lapatinib on quality of life of patients with trastuzumab-refractory HER2+ metastatic breast cancer. Ann Oncol. 2011;22:2582-90.

2. Dahlhoff M, Schafer M, Muzumdar S, Rose C, Schneider MR. ERBB3 is required for tumor promotion in a mouse model of skin carcinogenesis. Mol Oncol. 2015:9:1825-33.

3. Krahn G, Leiter U, Kaskel P, Udart M, Utikal J, Bezold G, Peter RU. Coexpression patterns of EGFR, HER2, HER3 and HER4 in non-melanoma skin cancer. Eur J Cancer. 2001;37:251-9.

4. Pinkas-Kramarski R, Soussan L, Waterman H, Levkowitz G, Alroy I, Klapper L, Lavi S, Seger R, Ratzkin BJ, Sela M, Yarden Y. Diversification of Neu differentiation factor and epidermal growth factor signaling by combinatorial receptor interactions. EMBO J. 1996;15:2452-67.

5. Alimandi M, Romano A, Curia MC, Muraro R, Fedi P, Aaronson SA, Di Fiore PP, Kraus MH. Cooperative signaling of ErbB3 and ErbB2 in neoplastic transformation and human mammary carcinomas. Oncogene. 1995; 10:1813-21.

6. Jaiswal BS, Kljavin NM, Stawiski EW, Chan E, Parikh C, Durinck S, Chaudhuri S, Pujara K, Guillory J, Edgar KA, et al. Oncogenic ERBB3 mutations in human cancers. Cancer Cell. 2013;23:603-17.

7. den Brok MH, Sutmuller RP, Nierkens S, Bennink EJ, Frielink C, Toonen LW, Boerman OC, Figdor CG, Ruers TJ, Adema GJ. Efficient loading of dendritic cells following cryo and radiofrequency ablation in combination with immune modulation induces anti-tumour immunity. $\mathrm{Br} J$ Cancer. 2006:95:896-905.

8. Linnemann C, van Buuren MM, Bies L, Verdegaal EM, Schotte R, Calis JJ, Behjati S, Velds A, Hilkmann H, Atmioui DE, et al. High-throughput epitope discovery reveals frequent recognition of neo-antigens by $\mathrm{CD}^{+}{ }^{+}$ T cells in human melanoma. Nat Med. 2015;21:81-5.

9. Lennerz , Fatho M, Gentilini C, Frye RA, Lifke A, Ferel D, Wolfel C, Huber C, Wolfel T. The response of autologous T cells to a human melanoma is dominated by mutated neoantigens. Proc Natl Acad Sci U S A. 2005;102:16013-8.

10. Rowe DE, Carroll RJ, Day CL Jr. Prognostic factors for local recurrence, metastasis, and survival rates in squamous cell carcinoma of the skin, ear, and lip. Implications for treatment modality selection. J Am Acad Dermatol. 1992;26:976-90.

\section{Acknowledgements}

Not applicable.

\section{Competing interests}

The authors declare that they have no competing interests. 